\title{
General Psychiatry New directions in anxiety disorder treatment
}

To cite: Rosenbaum J. New directions in anxiety disorder treatment. General Psychiatry 2019;32:e100166. doi:10.1136/ gpsych-2019-100166

Received 07 0ctober 2019 Revised 05 November 2019 Accepted 07 November 2019

Check for updates

(C) Author(s) (or their employer(s)) 2019. Re-use permitted under CC BY-NC. No commercial re-use. See rights and permissions. Published by BMJ.

${ }^{1}$ Department of Psychiatry, Massachusetts General Hospital, Boston, Massachusetts, USA

2Department of Psychiatry, Harvard Medical School, Boston, Massachusetts, USA

Correspondence to Jerry Rosenbaum; rosenbaum.jerrold@mgh. harvard.edu

Jerry Rosenbaum ${ }^{1,2}$

As this special volume indicates, we have multiple modalities and approaches for thinking about anxiety and its therapeutics. Our treatment approaches and understandings vary from the psychological and cognitive to the biological and pharmacological. We also assert that the underlying neurobiology, mechanisms and evolutionary psychology of anxiety are the best understood of any form of psychiatric disorder. Yet while most patients who suffer anxiety disorders can be helped, few are cured. Furthermore, while anxiety research is robust, as evidenced in this issue, the therapies and therapeutic outcomes of today look very much the same as 30 years ago. The most dramatically and acutely effective of pharmacological anxiolytic treatments are limited by challenges of tachyphylaxis, diversion and abuse, and withdrawal syndromes when discontinued. Therefore, in short, there remains work to be done and new approaches to be determined to better address this form of human suffering.

In this effort, it may be that our belief that we fully understand anxiety and its neurocircuitry is a distraction, the idea that it is simply the over-reactivity and hyperresponsiveness of fear circuitry, otherwise designed to keep us safe, that explains what we experience and what goes awry. Genetic risk profiling of other psychiatric disorders underscores the heterogeneity of risk for emotional and cognitive dysregulation. This observation implies that personalised psychiatry and the future of determining differences across individuals in brain connectivity, circuit activity, genetics and human experience will be the guide to how to treat individuals who suffer various forms of anxiety.

The phenomenology, the phenotypes of anxiety, are pleomorphic, including worry and panic, avoidance and rituals, rumination and physiological arousal that comprise a complex array of syndromes we call diagnoses.

I think of anxiety in analogy to the immune system, similarly hardwired by evolution to keep the organism safe from external threat and featuring a learning system that adapts itself to threats in the environment. Ideally, the immune system, like fear, activates when necessary and is precise and effective when needed; nonetheless, the immune system is associated with unpleasant manifestations when active (rubor, dolor, calor, tumour). In some cases, the response is excessive and does more damage to the organism than is necessary. The response can be worse than the threat in these cases. Furthermore, there are instances where the immune system turns on the self as in autoimmune disease where the system designed to be protective itself is the threat.

There may be more than analogy in this metaphor as we begin to understand the cross linking between inflammation and psychiatric diseases, including anxiety. Furthermore, as with triggers of inflammation, we use similar defences: avoid the provocative factors, avoid the threats, suppress the response with drugs, or even use systematic graduated exposure to retrain the system to recognise the provocation as safe, to make it more homeostatic. This metaphor about immune function serves a further use in attempting to explain anxiety to any who might otherwise trivialise the phenomenon and its often-disabling burdens.

Perhaps in this metaphor, the benzodiazepines are to severe anxiety what prednisone is to autoimmune disease, miraculous for some in the short term but weighed against the burdens of adverse effects and discontinuation down the road. Monoclonal antibody drugs have begun to replace prednisone, and we can imagine a time when we can downregulate anxiety without the physiological costs of addiction or tachyphylaxis. There is current interest for example in the endocannabinoid system and targets like fatty acid amide hydrolase and monoacylglycerol lipase for new anxiolytics. 
That humans are differentially vulnerable to acquiring anxiety disorders, similar to autoimmune disease, is underscored by the review of Clauss in this volume and hearkens back to work beginning in the early 1980s by researchers at Massachusetts General Hospital, including Biederman, Hirshfeld-Becker and myself. We determined that children of parents with panic disorder and agoraphobia were more likely to be behaviourally inhibited and through adolescence were more likely to manifest anxiety symptoms and social anxiety. ${ }^{1}$ Hirshfeld-Becker and colleagues ${ }^{2}$ created a family and child focussed cognitive behaviour therapy protocol that markedly reduced current and future symptoms, and this work convinced us to create a clinical programme to intervene early in children with or at risk for anxiety symptoms. Case reports from this approach are in this issue and underscore that meaningful treatment can be initiated early, a wonderful and remarkable advance.

There is still opportunity for the wise clinician to lead the field to new discovery. This year psychiatry lost an iconic investigator whose early observations in the clinic led us to rethink anxiety as a single phenomenon through what was termed pharmacological dissection. ${ }^{3}$ So we also at this time remember recently deceased Donald Klein, a provocative and innovator thinker, who gave us theories about panic provocation and novel physiological mechanisms as well as new therapeutic approaches that renewed interest in understanding therapeutics, biology, early development and family history all reflected in one way or another in the up to date contribution that is this issue.

Contributors JFR conceived of and wrote this editorial.

Funding The authors have not declared a specific grant for this research from any funding agency in the public, commercial or not-for-profit sectors.

Competing interests None declared.

Patient consent for publication Not required.

Provenance and peer review Commissioned; externally peer reviewed.

Open access This is an open access article distributed in accordance with the Creative Commons Attribution Non Commercial (CC BY-NC 4.0) license, which permits others to distribute, remix, adapt, build upon this work non-commercially, and license their derivative works on different terms, provided the original work is properly cited, appropriate credit is given, any changes made indicated, and the use is non-commercial. See: http://creativecommons.org/licenses/by-nc/4.0/.

\section{REFERENCES}

1 Biederman J, Petty C, Faraone SV, et al. Parental predictors of pediatric panic disorder/agoraphobia: a controlled study in high-risk offspring. Depress Anxiety 2005;22:114-20.

2 Hirshfeld-Becker DR, Masek B, Henin A, et al. Cognitive behavioral therapy for 4- to 7-year-old children with anxiety disorders: a randomized clinical trial. J Consult Clin Psychol 2010;78:498-510.

3 Klein DF. Delineation of two drug-responsive anxiety syndromes. Psychopharmacologia 1964;5:397-408.

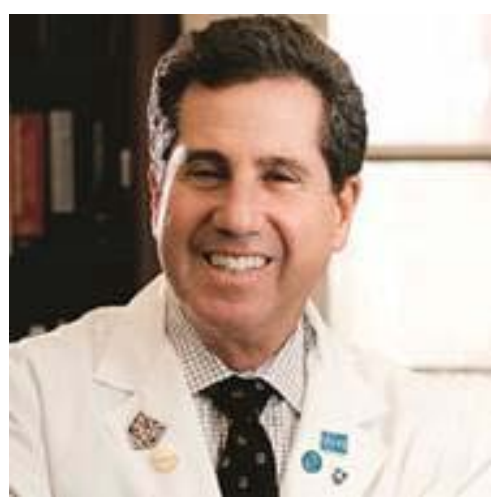

Dr. Jerrold F. Rosenbaum received his undergraduate degree from Yale College and his medical degree from Yale School of Medicine. He completed his residency and fellowship in Psychiatry at Massachusetts General Hospital, Harvard Medical School. After serving as the Chief of Psychiatry at Massachusetts General Hospital for 17 years, Dr. Rosenbaum now serves as the Director of the Center for Anxiety and Traumatic Stress Disorders. Dr. Rosenbaum is recognized as one of the world's foremost authorities on mood and anxiety disorders, with a special emphasis on pharmacotherapy of those conditions. He has authored more than 300 original articles and reviews and has published 12 books. His research contributions include extensive participation in the design and conduct of clinical trials of new therapies, the design and implementation of trials to develop innovative treatments for major depression, treatment resistant depression, and panic disorder, studies of psychopathology including comorbidity and subtypes, and studies of longitudinal course and outcomes of those disorders. 